\title{
Synthesis, characterization and catalytic properties of Y- $\beta$ zeolite composites
}

\author{
Qin Bo, Zhang Xiwen, Zhang Zhizhi, Ling Fengxiang and Sun Wanfu*
}

Fushun Research Institute of Petroleum and Petrochemicals, SINOPEC, Fushun, Liaoning 113001, China

(C) China University of Petroleum (Beijing) and Springer-Verlag Berlin Heidelberg 2011

\begin{abstract}
Y- $\beta$ zeolite composites were hydrothermally synthesized by using high silica Y zeolite as the precursor and characterized by XRD, $\mathrm{N}_{2}$ adsorption, SEM and IR spectra of pyridine. The result showed that the $\mathrm{N}_{2}$ adsorption-desorption isotherm of the zeolite composites had a distinct hysteresis loop, and the SEM result showed that the zeolite composites had a different morphology from $Y, \beta$ and the corresponding physical zeolite mixture. The acid catalytic performance of the zeolite composite catalysts was investigated in the hydrocracking and hydroisomerization of n-octane, and the results showed that the composite materials exhibited an excellent hydrocracking activity and good hydroisomerization performance. The yield of $\mathrm{i}-\mathrm{C}_{4}$ over the zeolite composite catalyst was $4.45 \%$ higher than that on the corresponding zeolite mixture in the n-octane hydrocracking process at $553 \mathrm{~K}$. The isomerization ability of n-octane over the composite catalyst was 3.6 fold that of the corresponding mixture at $503 \mathrm{~K}$.
\end{abstract}

Key words: Zeolite composites, synthesis, characterization, hydrocracking, hydroisomerization

\section{Introduction}

As an acid catalytic material, Zeolite Y has been widely used in petroleum refining (Solis et al, 2004), because of its appropriate pore structure, high acidity and good thermal and hydrothermal stability (Bataille et al, 2001; Li et al, 1999; Bendezu et al, 2000; Kunisada et al, 2004). A large amount of work has been done worldwide to improve zeolite Y (Scherzer, 1984; Isaev and Fripiat, 1999). Zeolite $\beta$ has attracted many researchers' attention because of its good hydroisomerization activity and tolerance to carbon residue (Angevien et al, 1985; Ali et al, 2002). Previous studies of the two zeolites were mainly focused on their modification, catalytic performance and application (Kunisada et al, 2004; Ali et al, 2002; Marin et al, 2005; Hassan et al, 2001). Recently, with the development of zeolite composites (Zheng et al, 2009a; 2009b), researchers have found that zeolite composites have different catalytic performance in hydrocracking and FCC processes compared with the corresponding physical zeolite mixture (Wang et al, 2007; Chen et al, 2003; Zhang et al, 2010). Zhang et al (2010) reported a method for synthesizing Y- $\beta$ zeolite composites and investigated its hydrocracking performance using vacuum gas oil (VGO) as feedstock. The result showed that the Y- $\beta$ composite zeolite as a hydrocracking catalyst for VGO could increase the heavy naphtha yield by $5.61 \mathrm{wt} \%$ and the jet fuel yield by $11.52 \mathrm{wt} \%$, compared with the corresponding physical mixture of $Y$ and $\beta$ zeolites.

In this paper, a simple method is presented for

*Corresponding author. email: sunwanfu.fshy@sinopec.com

Received September, 2010 synthesizing Y- $\beta$ zeolite composites by using high silica $\mathrm{Y}$ as precursor. XRD, $\mathrm{N}_{2}$ adsorption, SEM and IR spectra of pyridine were used to characterize the as-synthesized Y- $\beta$ composite zeolite samples. Hydrocracking and hydroisomerization of n-octane were selected as model acidcatalyzed reactions to evaluate the catalytic performance of the as-synthesized composite zeolite catalysts and to compare it with that of the corresponding physical mixture.

\section{Experimental}

\subsection{Synthesis of $Y-\beta$ composite zeolites and preparation of catalysts}

Y- $\beta$ zeolite composites were synthesized in a Teflon-lined autoclave under static hydrothermal conditions. Typically, $0.54 \mathrm{~g} \mathrm{NaOH}, 10.0 \mathrm{~g}$ tetraethylammonium bromide (TEABr) and $4.0 \mathrm{ml} \mathrm{NH}_{4} \mathrm{OH}$ were added to $35.0 \mathrm{ml}$ distilled water to form a clear solution, then $12.5 \mathrm{~g} \mathrm{NaY}\left(\mathrm{SiO}_{2} / \mathrm{Al}_{2} \mathrm{O}_{3}=5.0\right.$, Fushun Research Institute of Petroleum and Petrochemicals) was added to the solution. The mixture was stirred at room temperature for $0.5 \mathrm{~h}$, and then $20.0 \mathrm{ml}$ silica sol was added slowly under vigorous stirring. The final mixture was then put into the autoclave and heated at $413 \mathrm{~K}$ for $120-192 \mathrm{~h}$. The as-synthesized solid product (Y- $\beta$ zeolite composites) was filtered, washed with deionized water, dried in air at $373 \mathrm{~K}$, and then calcined at $823 \mathrm{~K}$ in air for $3 \mathrm{~h}$ in a muffle furnace. The Y- $\beta$ zeolite composites was denoted as Y- $\beta$.

A physical mixture of $Y$ and $\beta$ zeolites (denoted as $Y+\beta$ ) was prepared by mixing the pure $\mathrm{Y}\left(\mathrm{SiO}_{2} / \mathrm{Al}_{2} \mathrm{O}_{3}=5.0\right.$, Fushun Research Institute of Petroleum and Petrochemicals, China) and pure $\beta\left(\mathrm{SiO}_{2} / \mathrm{Al}_{2} \mathrm{O}_{3}=25.0\right.$, Fushun Research Institute of Petroleum and Petrochemicals, China) zeolites, and used as 
the references.

The $\mathrm{NH}_{4}^{+}$-type of the samples (the zeolite composites $\mathrm{Y}-\beta$ and the corresponding physical mixture $Y+\beta$ ) was obtained by ion exchange with $0.5 \mathrm{M} \mathrm{NH}_{4} \mathrm{NO}_{3}$ solution for $2 \mathrm{~h}$ at room temperature. The ion exchange was repeated twice, until the content of sodium in the zeolites was less than $0.15 \mathrm{wt} \%$. The proton-type zeolite was obtained by calcining the $\mathrm{NH}_{4}{ }^{+}$-type samples at $773 \mathrm{~K}$ for $5 \mathrm{~h}$.

The catalysts were prepared by the incipient wetness impregnation method. A required amount of metal ion $(\mathrm{Ni}$, Mo or Pt) solution was added to proton-type zeolite samples at room temperature. The metal-loaded samples were then dried at $393 \mathrm{~K}$ overnight and calcined at $723 \mathrm{~K}$ in air for 3 $\mathrm{h}$ producing the hydrocracking catalysts $\mathrm{Ni}-\mathrm{Mo} / \mathrm{Y}-\mathrm{\beta}$ and $\mathrm{Ni}-$ $\mathrm{Mo} / \mathrm{Y}+\beta$ containing $8.0 \mathrm{wt} \% \mathrm{Mo}$ and $2.4 \mathrm{wt} \% \mathrm{Ni}$ and the hydroisomerization catalysts $\mathrm{Pt} / \mathrm{Y}-\beta$ and $\mathrm{Pt} / \mathrm{Y}+\beta$ containing 0.6 wt $\%$ Pt.

\subsection{Characterization}

XRD patterns of the samples were recorded using a Rigaku D/max-2500 X-ray powder diffractometer (Rigaku, Japan), with $\mathrm{CuK} \alpha$ radiation at $40 \mathrm{kV}$ and $80 \mathrm{~mA}$. A working plot of physical mixtures $\mathrm{Y}+\beta$ can be obtained by plotting the intensity of the diffraction peak at $2 \theta=6.16$ versus the mass fraction of $\mathrm{Y}$ zeolite by measuring a series of physical mixtures with known mass fractions of Y zeolite. The mass fraction of $\mathrm{Y}$ zeolite in the composite $\mathrm{Y}-\beta$ can be therefore estimated from the intensity of the XRD diffraction peak at $2 \theta=6.16$, which is the characteristic peak of Y zeolite. The nitrogen adsorption and desorption isotherms at $77 \mathrm{~K}$ were measured using a Micromeritics ASAP2400 system (Micromeritics Co., USA). The SEM morphology was obtained on a JEOL JSM-6301F scanning electron microscope $(25$ $\mathrm{kV}, 10 \mu \mathrm{A})(\mathrm{JEOL}$, Tokyo, Japan). The TEM examination of the prepared materials was undertaken with a Tecnai G220 field emission electron microscope (JEOL, Tokyo, Japan). Samples were prepared by dispersing the powder of zeolite composites $\mathrm{Y}-\beta$ or corresponding physical mixtures $\mathrm{Y}+\beta$ in methanol via sonication for about $20 \mathrm{~min}$ followed by evaporation on a 300 mesh continuous carbon film TEM grid. IR spectra of the samples were recorded on a BIO-RAD FTIR spectrometer (FTS165) (BIO-RAD Co., USA). The acid types (i.e. Brønsted or Lewis type) were recorded by in-situ pyridine adsorption. XPS (X-ray photoelectron spectroscopy) was performed on a Multilab-2000 spectrometer equipped with a hemispherical electron analyzer and an $\operatorname{MgK} \alpha$ X-ray source (ThermoFisher Co., USA).

\subsection{Test of catalytic performance of catalyst}

The test of catalytic performance of the catalysts for n-octane was carried out on a standard micro-activity test (MAT) unit WF-9100П (Fushun Research Institute of Petroleum and Petrochemicals, China). The reactor was connected to an online GC-8A gas chromatograph (Shimadzu Corporation, Kyoto, Japan). The reaction products were analyzed using a $150 \mathrm{~m} \times 0.20 \mathrm{~mm} \times 0.32 \mu \mathrm{m}$ capillary column and a flame ionization detector (FID) detector.

Experimental conditions: For hydrocracking: $\mathrm{H}_{2}$ to $\mathrm{n}$-octane volume ratio of 1000 , pressure of $3.0 \mathrm{MPa}$, temperature of 510-570 K, liquid hourly space velocity $(\mathrm{LHSV})=1.5 \mathrm{~h}^{-1}$; For hydroisomerization: $\mathrm{H}_{2}$ to n-octane volume ratio of 1000 , pressure of $0.3 \mathrm{MPa}$, temperature of $470-520 \mathrm{~K}, \mathrm{LHSV}=3 \mathrm{~h}^{-1}$.

\section{Results and discussion}

\subsection{XRD}

Fig. 1 shows the XRD patterns of the Y- $\beta$ zeolite composites with the same contents of $Y$ and $\beta$. The characteristic peaks corresponding to zeolites $Y$ and $\beta$ can be observed, indicating the co-existence of $Y$ and $\beta$ zeolite phases in the composite Y- $\beta$. The analysis by XRD also showed that the Y- $\beta$ zeolite composites prepared from $\beta$ zeolite intergrowth on $\mathrm{Y}$ zeolite was of high crystallinity, although Y zeolite was treated by alkali solution at $413 \mathrm{~K}$ during the synthesis process of $\mathrm{Y}-\beta$ zeolite composites. This is because that the formation of the shell layer of $\beta$ zeolite also prevents excessive dissolution of Y zeolite crystals by the synthesis solution (Zhang et al, 2010; Bouizi et al, 2006).

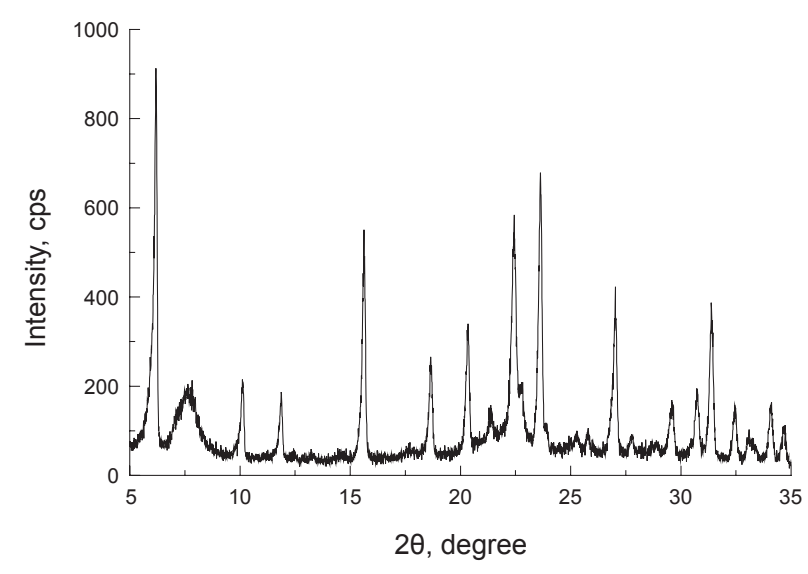

Fig. 1 XRD pattern of a Y- $\beta$ zeolite composite

\section{2 $\mathrm{N}_{2}$ adsorption-desorption isotherms}

The formation of Y- $\beta$ zeolite composites induced a significant change in the pore structure. $\mathrm{N}_{2}$ adsorptiondesorption results of the as-synthesized Y- $\beta$ composite samples and the corresponding physical mixture $\mathrm{Y}+\beta$ samples are shown in Fig. 2. A large hysteresis loop appears in the adsorption-desorption isotherm of the zeolite composites $\mathrm{Y}-\beta$, and the pore size distributions are centered at $35 \AA$ and $400 \AA$, indicating the existence of mesopores in the zeolite composites. This is attributed to the treatment of $\mathrm{Y}$ zeolite with alkali solution and the polycrystalline aggregation of $\beta$ zeolite. During the synthesis process, Y zeolite as the precursor was etched by the synthesis solution and the silica in the framework was partially dissolved, causing enlargement of micropores and resulting in the formation of mesopores (Zhang et al, 2010). The polycrystalline aggregation of $\beta$ zeolites around zeolite Y particles also played an important role in the formation of mesopores in the composites. The mesopore structure helped improve the hydrocracking of bulky molecules. 


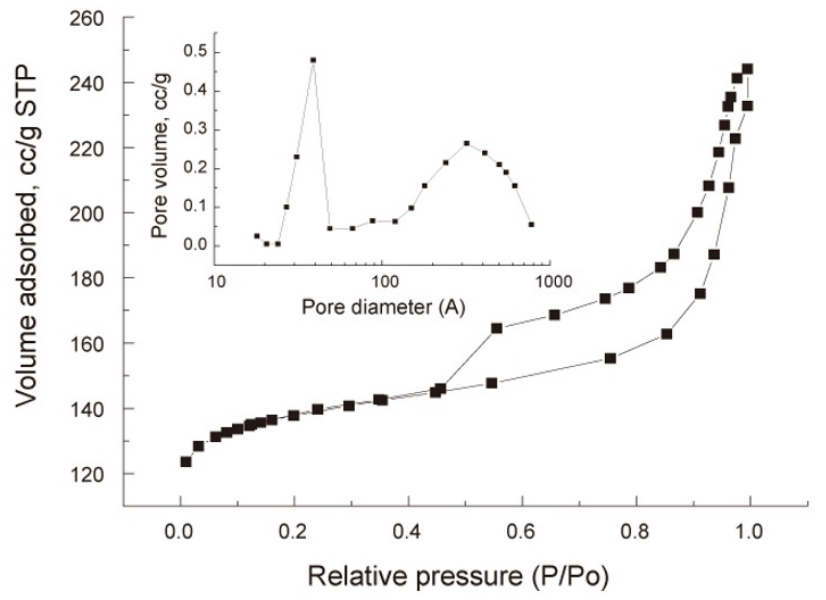

Fig. $2 \mathrm{~N}_{2}$ adsorption-desorption isotherm and pore size distribution curve of a Y- $\beta$ zeolite composite
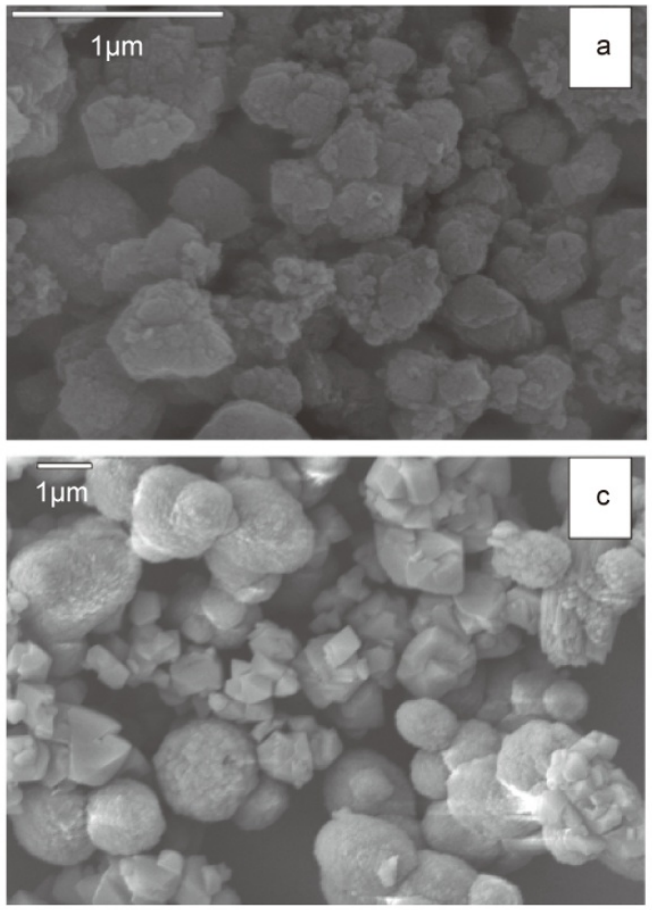

\subsection{SEM and XPS}

As shown in Fig. 3, the Y- $\beta$ zeolite composites show a new morphology, different from $\mathrm{Y}$ or $\beta$ zeolite. The zeolite composite Y- $\beta$ has a rough irregular morphology (Fig. 3a and b), rather different from the corresponding mixture in which single $\mathrm{Y}$ and single $\beta$ crystals are clearly observed separate from each other (Fig. 3c). The polycrystalline aggregate of zeolite $\beta$ around $\mathrm{Y}$ zeolite particles is composed of laminar polyhedron nano-particles. The results here agree well with that reported (Zhang et al, 2010). It can be inferred from Fig. $3 d$ that the as-synthesized Y- $\beta$ zeolite composites has an obvious core-shell structure. XPS analysis was carried out to further understand the distribution of $\mathrm{Al}$ and $\mathrm{Si}$ species over the surface ( $10 \mathrm{~nm}$ thickness) of Y- $\beta$ zeolite composites. The results showed that the shell layer zeolite of $\mathrm{Y}-\beta$ zeolite composites had a $\mathrm{SiO}_{2} / \mathrm{Al}_{2} \mathrm{O}_{3}$ ratio of 25.9 , very close to the $\mathrm{SiO}_{2} / \mathrm{Al}_{2} \mathrm{O}_{3}$ ratio of $\beta$ zeolite. The above-mentioned TEM and


Fig. 3 SEM and TEM images of zeolite composite and the corresponding mixture SEM images: a and b: the zeolite composite; $\mathrm{c}$ : the corresponding mixtures; d: TEM image of the composite. This shows that the as-synthesized zeolite composite sample has a Y zeolite core and a $\beta$ zeolite polycrystalline shell.

XPS results showed that the as-synthesized zeolite composite $\mathrm{Y}-\beta$ posses a core-shell structure of $\mathrm{Y}$ zeolite core and $\beta$ zeolite polycrystalline shell.

\subsection{Catalytic performance of catalysts}

\subsubsection{Physico-chemical properties of catalysts}

The physico-chemical properties of the supported catalysts are listed in Table 1. The results showed that the surface area and pore volume of the Y- $\beta$ zeolite composites are larger than those of the corresponding mixtures. For investigation of acid sites and their distribution, pyridine was selected as the probe molecule. The catalysts with different metal loadings resulted in great differences in the amount of Brønsted (B) and Lewis (L) acid. The Pt and Ni-Mo loading in the Y- $\beta$ catalysts increased the B- and L-acid amount, respectively, compared with the $\mathrm{Y}+\beta$ catalysts.

Table 1 The properties of cataly

\begin{tabular}{ccccc}
\hline Catalysts & $\begin{array}{c}\mathrm{Ni}-\mathrm{Mo} / \\
\mathrm{Y}-\beta\end{array}$ & $\begin{array}{c}\mathrm{Ni}-\mathrm{Mo} / \\
\mathrm{Y}+\beta\end{array}$ & $\mathrm{Pt} / \mathrm{Y}-\beta$ & $\mathrm{Pt} / \mathrm{Y}+\beta$ \\
\hline Surface $\mathrm{area} \mathrm{m}^{2} \cdot \mathrm{g}^{-1}$ & 550 & 431 & 635 & 543 \\
Micropore area, $\mathrm{m}^{2} \cdot \mathrm{g}^{-1}$ & 402 & 341 & 456 & 422 \\
Pore volume, $\mathrm{mL} \cdot \mathrm{g}^{-1}$ & 0.29 & 0.24 & 0.33 & 0.28 \\
Micropore volume, $\mathrm{mL} \cdot \mathrm{g}^{-1}$ & 0.16 & 0.14 & 0.18 & 0.17 \\
B acid, $\mathrm{mmol} \cdot \mathrm{g}^{-1}$ & 0.22 & 0.29 & 0.46 & 0.44 \\
$\mathrm{~L}$ acid, $\mathrm{mmol} \cdot \mathrm{g}^{-1}$ & 0.80 & 0.91 & 0.74 & 0.58 \\
\hline
\end{tabular}




\subsubsection{Test of catalytic performance}

Fig. 4 shows the conversion of n-octane in hydrocracking over catalysts $\mathrm{Ni}-\mathrm{Mo} / \mathrm{Y}-\beta$ and $\mathrm{Ni}-\mathrm{Mo} / \mathrm{Y}+\beta$ at different temperatures. It can be seen that the hydrocracking activity of catalysts $\mathrm{Ni}-\mathrm{Mo} / \mathrm{Y}-\beta$ and $\mathrm{Ni}-\mathrm{Mo} / \mathrm{Y}+\beta$ for $\mathrm{n}$-octane increased with increasing temperature, and that the catalytic activity of catalyst $\mathrm{Ni}-\mathrm{Mo} / \mathrm{Y}-\beta$ was higher than that of $\mathrm{Ni}-\mathrm{Mo} / \mathrm{Y}+\beta$. At low temperature, such as at $513 \mathrm{~K}$, the conversion of n-octane over catalyst $\mathrm{Ni}-\mathrm{Mo} / \mathrm{Y}-\beta$ was about $91 \mathrm{wt} \%$, much higher than $67 \mathrm{wt} \%$ over $\mathrm{Ni}-\mathrm{Mo} / \mathrm{Y}+\beta$. Compared with catalyst $\mathrm{Ni}-$ $\mathrm{Mo} / \mathrm{Y}+\beta$, the conversion of n-octane over the catalyst Ni-Mo/ $\mathrm{Y}-\beta$ increased gently with increasing reaction temperature, especially after $550 \mathrm{~K}$. With increasing temperature from 513 $\mathrm{K}$ to $573 \mathrm{~K}$, the difference between $\mathrm{n}$-octane conversions over catalyst Ni-Mo/Y- $\beta$ and $\mathrm{Ni}-\mathrm{Mo} / \mathrm{Y}+\beta$ decreased from $24 \%$ to $7 \%$. The high conversion of n-octane over catalyst Ni-Mo/ Y- $\beta$ may be attributed to the mesopore structure as observed in the SEM and $\mathrm{N}_{2}$ adsorption-desorption experiments. The mesopore structure is favorable to transporting reactants to the active sites and transporting products departing from the active sites in its channel, and favorable to accessing strong acid sites (Zheng et al, 2009a; 2009b). The hydrocracking products at $553 \mathrm{~K}$ are listed in Table 2 . The yield of $\mathrm{i}-\mathrm{C}_{4}$ over $\mathrm{Ni}-\mathrm{Mo} / \mathrm{Y}-\beta$ catalyst was $45.0 \mathrm{wt} \%$, higher than the $40.5 \mathrm{wt} \%$ over $\mathrm{Ni}-\mathrm{Mo} / \mathrm{Y}+\beta$.

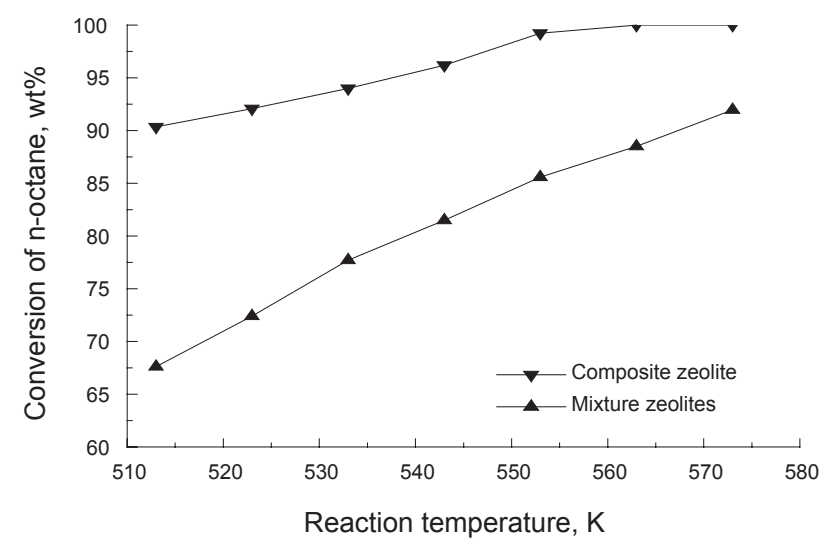

Fig. 4 Conversion of n-octane hydrocracking over zeolite composite catalyst $\mathrm{Ni}-\mathrm{Mo} / \mathrm{Y}-\beta$ and zeolite mixture catalyst $\mathrm{Ni}-\mathrm{Mo} / \mathrm{Y}+\beta$ at different temperatures

Table 2 Hydrocracking products

\begin{tabular}{ccc}
\hline \multirow{2}{*}{ Products, wt $\%$} & \multicolumn{2}{c}{ Catalyst } \\
\cline { 2 - 3 } & $\mathrm{Ni}-\mathrm{Mo} / \mathrm{Y}-\beta$ & $\mathrm{Ni}-\mathrm{Mo} / \mathrm{Y}+\beta$ \\
$\mathrm{n}-\mathrm{C}_{3}$ & 13.04 & 8.83 \\
$\mathrm{i}-\mathrm{C}_{4}$ & 44.99 & 40.54 \\
$\mathrm{n}-\mathrm{C}_{4}$ & 15.55 & 10.34 \\
$\mathrm{i}-\mathrm{C}_{5}$ & 16.87 & 15.53 \\
$\mathrm{n}-\mathrm{C}_{5}$ & 4.51 & 1.90 \\
$\mathrm{i}-\mathrm{C}_{6}$ & 3.44 & 3.28 \\
$\mathrm{n}-\mathrm{C}_{6}$ & 0.85 & 0.64 \\
$\mathrm{i}-\mathrm{C}_{8}$ & - & 4.52 \\
$\mathrm{n}-\mathrm{C}_{8}$ & 0.76 & 14.4 \\
\hline
\end{tabular}

Fig. 5 shows the i-octane yield in hydroisomerization of n-octane over catalysts $\mathrm{Pt} / \mathrm{Y}-\beta$ and $\mathrm{Pt} / \mathrm{Y}+\beta$ at different temperatures. The $\mathrm{i}$-octane yield on $\mathrm{Pt} / \mathrm{Y}-\beta$ catalyst was much higher than that on $\mathrm{Pt} / \mathrm{Y}+\beta$. The products of $\mathrm{n}$-octane hydroisomerization at $503 \mathrm{~K}$ are listed in Table 3. The conversion of n-octane over $\mathrm{Pt} / \mathrm{Y}$ - $\beta$ was 3.7-fold that on $\mathrm{Pt} /$ $\mathrm{Y}+\beta$. The yields of mono-branched and di-branched isomers on $\mathrm{Pt} / \mathrm{Y}-\beta$ were $27.97 \mathrm{wt} \%$ and $11.54 \mathrm{wt} \%$, respectively, much higher than those on $\mathrm{Pt} / \mathrm{Y}+\beta$.

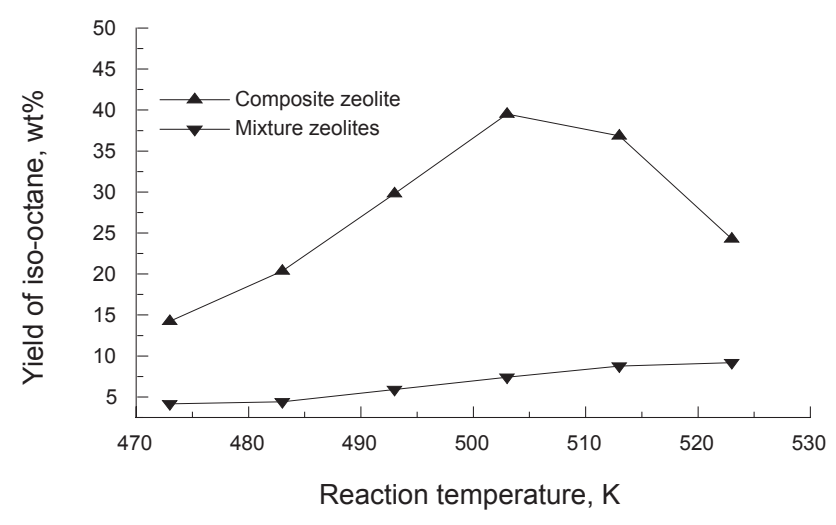

Fig. 5 n-Octane hydroisomerization over zeolite composite catalyst $\mathrm{Pt} / \mathrm{Y}-\beta$ and zeolite mixture catalyst $\mathrm{Pt} / \mathrm{Y}+\beta$ at different temperatures

Table 3 Hydroisomerization products

\begin{tabular}{ccc}
\hline \multirow{2}{*}{ Products } & \multicolumn{2}{c}{ Catalyst } \\
\cline { 2 - 3 } & $\mathrm{Pt} / \mathrm{Y}-\beta$ & $\mathrm{Pt} / \mathrm{Y}+\beta$ \\
\hline Conversion of n-octane, wt $\%$ & 52.3 & 13.8 \\
Mono-branched isomers, wt $\%$ & 28.0 & 5.91 \\
Di-branched isomers, wt $\%$ & 11.5 & 1.45 \\
Cyc-C $_{8}, \mathrm{wt} \%$ & 0.21 & 0.17 \\
Cracking product, wt $\%$ & 12.60 & 6.24 \\
Isomerization product/cracking product ratio & 3.14 & 1.19 \\
\hline
\end{tabular}

Apparently, zeolite composite catalysts have superior hydrogenation activity. It is known that catalytic hydrogenation reaction can take place on both metallic sites and acid sites close to the metal particles, implying hydrogen spillover from the metal surface or the metal-support boundary. Zeolite composite catalysts with more surface acid sites supply extra active sites for hydrogenation (Zheng et al, 2009a; 2009b). Hence, their activity is higher than zeolite mixture catalysts. The high activity of zeolite composite catalysts can be explained by their mesoporous structure. The mesoporous structure created in the zeolite composites may lead to better dispersion of metal particles (Li et al, 2009) and more metal active sites than zeolite mixture of $\mathrm{Y}$ and $\beta$ supports. The high Ni-Mo (or Pt) dispersion can increase the metal surface for reactant conversion and the hydrogen dissociation on metal, hence is favorable to hydrogen spillover. In addition, the high hydrogenation activity on zeolite composite catalysts can be achieved by improving the 
transportation of the reactants to and from the active sites in its channels, and more acid sites can be easily obtained due to the existence of the mesopores.

\section{Conclusions}

The Y- $\beta$ zeolite composites were successfully synthesized with a more feasible method. The characterization results showed the morphology of as-synthesized Y- $\beta$ zeolite composite is different from the single $\mathrm{Y}$ and $\beta$ zeolites, and a new mesopores structure was created in the as-synthesized zeolite composite. Zeolite composites displayed high hydrocracking activity and good hydroisomerization of n-octane, resulting from the introduction of the mesopores structure, which is attributed to enhanced dispersion of the supported metal particles as well as improved acid sites accessibility.

\section{References}

Ali M A, Tasumi T and Masuda T. Development of heavy oil hydrocracking catalysts using amorphous silica-alumina and zeolites as catalyst supports. Appl. Catal. A. 2002. 233 (1-2): 77-90

Angevien J P, Mitchell M K, Oleck M S, et al. US Patent 4612108. 1985

Bataille F, Lemberton J L, Pérot G, et al. Sulfided Mo and CoMo supported on zeolite as hydrodesulfurization catalysts 1: Transformation of dibenzothiophene and 4,6-dimethyldibenzothiophene. Appl. Catal. A: Gen. 2001. 220(1-2) : 191-205

Bendezu S, Cid R, Firro J L G, et al. Thiophene hydrodesulfurization on sulfided Ni, W and NiW/USY zeolite catalysts: Effect of the preparation method. Appl. Catal. A. 2000. 197(1): 47-60

Bouizi Y, Rouleau L, Valtchev V P, et al. Factors controlling the formation of core-shell zeolite-zeolite composites. Chem. Mater. 2006. 18(20): 4959-4966

Chen H L, Shen B J and Pan H F. Conversion of vegetable oil to biodiesel using ultrasonic irradiation. Chem. Lett. 2003. 32(8): 716

Hassan A, Ahmed S, Ali M A, et al. A comparison between $\beta$ - and USY- zeolite-based hydrocracking catalysts. Appl. Catal. A 2001. 220(12): $59-68$

Isaev $\mathrm{Yu}$ and Fripiat $\mathrm{J} \mathrm{J}$. A lewis acid site-activated reaction in zeolites: thiophene acylation by butyryl chloride. J. Catal. 1999. 182(1): 257263

Kunisada N, Choi K and Korai Y. Optimum coating of USY as a support component of NiMoS on alumina for deep HDS of gas oil. Appl. Catal.A. 2004. 276(1-2): 51-59

Li D, Nishishjima A, Morris D E, et al. Activity and structure of hydrotreating $\mathrm{Ni}, \mathrm{Mo}$, and Ni-Mo sulfide catalysts supported on $\gamma-\mathrm{Al}_{2} \mathrm{O}_{3}$-USY zeolite. J. Catal. 1999. 188(1): 111-124

Li Y, Liu S, Xie S et al. Promoted metal utilization capacity of alkalitreated zeolite: Preparation of Zn/ZSM-5 and its application in 1-hexene aromatization. Applied Catalysis A: General. 2009. 360: 8-16

Marin C, Escobar J, Galvan E, et al. Light straight-run gas oil hydrotreatment over sulfided $\mathrm{CoMoP} / \mathrm{Al} 2 \mathrm{O} 3$-USYzeolite catalysts. Fuel Process. Technol. 2005. 86(4): 391-405

Scherzer J. Catalytic Materials: Relationship between Structure and Reactivity, ACS Monograph, No. 248, Washington, DC. 1984. 157159

Solis D, Klimova T, Cuevas R, et al. Hydrodesulfurization of gas oils over NiMo/A12O3-H(or Ni)NaY zeolite hybrid catalysts. Catal. Today. 2004. 98(1-2): 201-206

Wang P, Shen B J and Gao J S. Synthesis of MAZ/ZSM-5 composite zeolite and its catalytic performance in FCC gasoline aromatization. Catal. Commun. 2007. 8(7): 1161-1166

Zhang X W, Guo Q, Qin B, et al. Structural features of binary microporous zeolite composite Y-beta and its hydrocracking performance. Catal. Today. 2010. 149: 212-217

Zheng J J, Ma J H, Wang Y, et al. Synthesis and catalytic property of a zeolite composite for preparation of dimethyl ether from methanol dehydration. Catal. Lett. 2009a. 130(3-4): 672-678

Zheng J J, Zhang X W, Wang Y, et al. Synthesis and catalytic performance of a bi-phase core-shell zeolite composite. J Porous Mater. 2009b. 16(6): 731-736

(Edited by Zhu Xiuqin) 